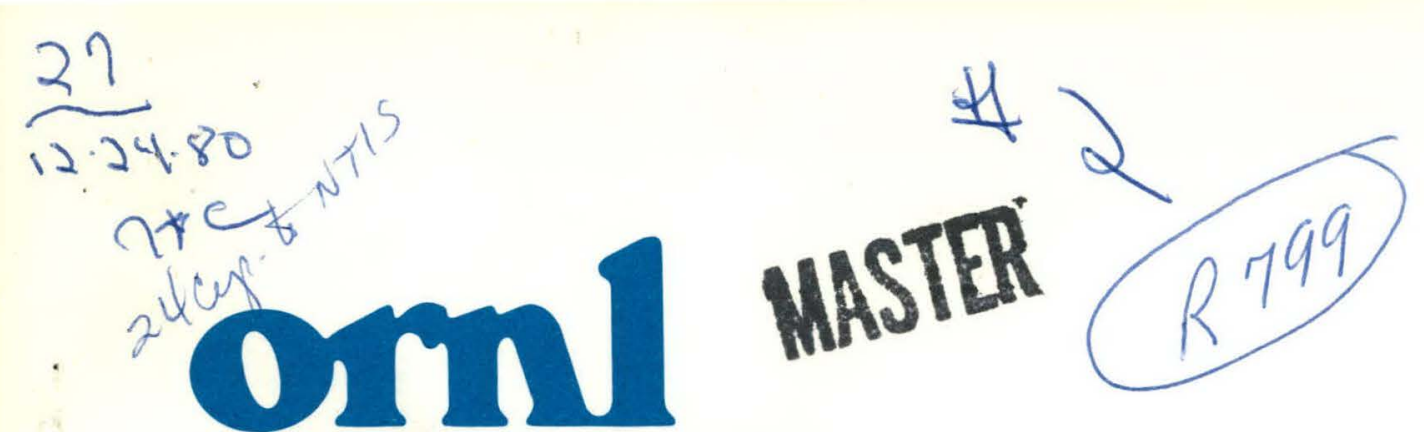

\title{
A CAMAC Modular Programmable Function Generator
}

\section{UNION \\ CARBIDE}

G. W. Turner

S. Suehiro

R. W. Hendricks

OPERATED BY

UNION CARBIDE CORPORATION FOR THE UNITED STATES DEPARTMENT OF ENERGY 


\section{DISCLAIMER}

This report was prepared as an account of work sponsored by an agency of the United States Government. Neither the United States Government nor any agency Thereof, nor any of their employees, makes any warranty, express or implied, or assumes any legal liability or responsibility for the accuracy, completeness, or usefulness of any information, apparatus, product, or process disclosed, or represents that its use would not infringe privately owned rights. Reference herein to any specific commercial product, process, or service by trade name, trademark, manufacturer, or otherwise does not necessarily constitute or imply its endorsement, recommendation, or favoring by the United States Government or any agency thereof. The views and opinions of authors expressed herein do not necessarily state or reflect those of the United States Government or any agency thereof. 


\section{DISCLAIMER}

Portions of this document may be illegible in electronic image products. Images are produced from the best available original document. 


\section{Printed in the United States of America. Available from National Technical Information Service I.I S Department of Commerce 5285 Port Royal Road, Springfield, Virginia 22161 NTIS price codes-Printed Copy: A03 Microfiche A01}

This report was prepared as an account of work sponsored by an agency of the United States Government. Neither the United States Government nor any agency thereof, nor any of their employees, makes any warranty, express or implied, or assumes any legal liability or responsibility for the accuracy, completeness, or usefulness of any information, apparatus, product, or process disclosed, or represents that its use would not infringe privately owned rights. Reference herein to any specific commercial product, process, or service by trade name, trademark, manufacturer, or otherwise, does not necessarily constitute or imply its endorsement, recommendation, or favoring by the United States Government or any agency thereof. The views and opinions of authors expressed herein do not necessarily state or reflect those of the United States Government or any agency thereof. 
Contract No. $W-7405-e n g-26$

Metals and Ceramics Division

A CAMAC MODULAR PROGRAMMABLE FUNCTION GENERATOR

G. W. Turner, S. Suehiro, and R. W. Hendricks

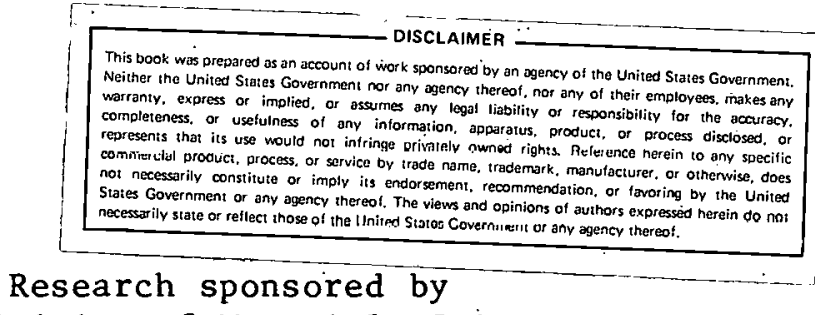

the Division of Materials Science

of the National Science Foundation

under grants to the University of Massachusetts

and to the Oak Ridge National Laboratory

and

by the Basic Energy Sciences Program

of the U.S. Department of Energy

Date Published: December 1980

OAK RIDGE NATIONAL LABORATORY

Oak Ridge, Tennessee 37830

operated by

UNION CARB IDE CORPORATION

for the

DEPARTMENT OF ENERGY 
THIS PAGE

\section{WAS INTENTIONALLY \\ LEFT BLANK}


CONTENTS

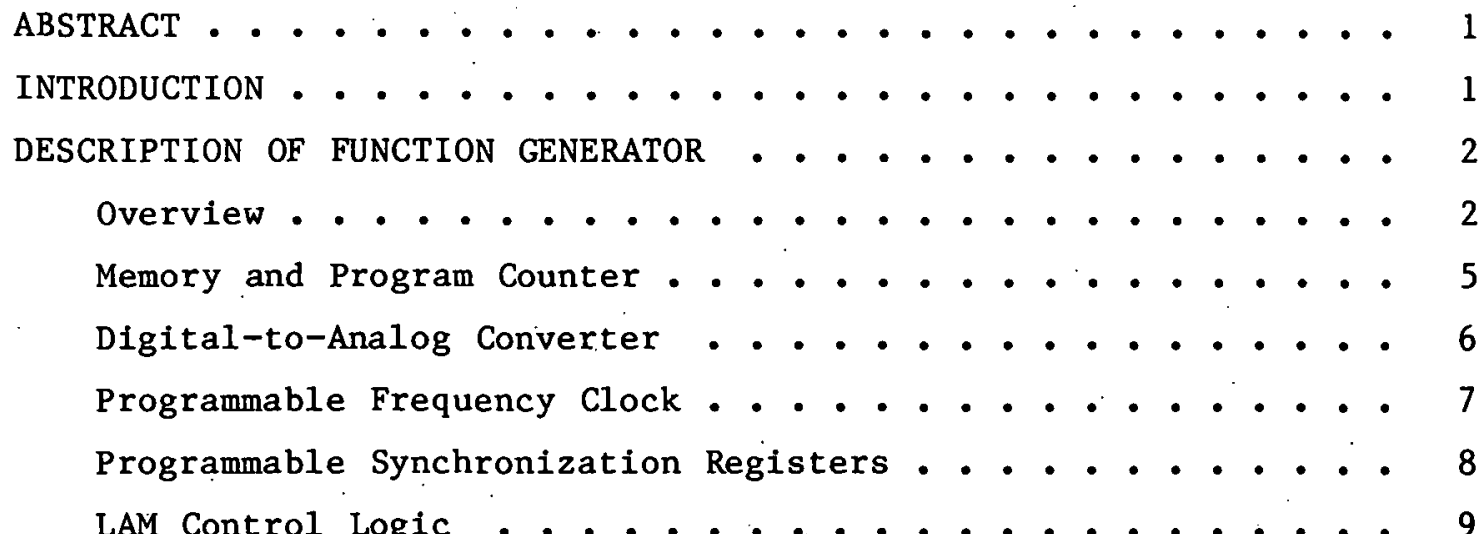




\title{
A CAMAC MODULAR PROGRAMMABLE FUNCTION GENERATOR
}

\author{
G. W. Turner, ${ }^{*}$ S. Suehiro, ${ }^{\dagger}$ and .R. W. Hendricks
}

\begin{abstract}
A CAMAC modular programmable function generator has been developed. The device contains a 1024 word by 12-bit memory, a 12-bit digital-to-analog converter with a 600 ns settling time, an 18-bit programmable frequency register, and two programmable trigger output registers. The trigger registers can produce programmed output logic transitions at various (binary) points in the output function curve, and are used to synchronize various other data acquisition devices with the function curve.
\end{abstract}

\section{INTRODUCTION}

In our laboratory small-angle $x$-ray and neutron scattering experiments are performed on instruments which are operated with pinhole collimation and which are equipped with two-dimensional position sensitive detectors.1-3 It has been found that the data acquisition rates with these instruments are sufficiently high that dynamic experiments performed during crystallization of polymers in situ in the x-ray beam are feasible. 4 In addition, the high speed and the time-switching capabilities of the data acquisition system available on these instruments ${ }^{1}$ lead one of us (RWH) to propose that dynamic experiments performed in situ during the mechanical deformation of pulymer1c and biological samples could be performed.1,5,6 For such experiments to be successful, it is necessary to: (1) deform the sample under programmably variable stress-strain relationships, (2) record the stress-strain during the deformation, (3) synchronize the acquisition

\footnotetext{
* Instrumentation and Controls Division.

† On assignment to Oak Ridge National Laboratory from the Pulymer Research Institute, University of Massachusetts, Amherst, MA 01003; permanent address: Department of Polymer Chemistry, Faculty of Engineering, Kyoto University, Kyoto 606, Japan.
} 
of the small-angle scattering diffraction pattern with the deformation, and (4) switch between acquisition arrays in memory at known and programmable times in the deformation cycle.

The availability of a fast-response CAMAC crate controller ${ }^{7}$ for the ModComp computers used with our small-angle scattering cameras made a CAMAC data acquisition system a logical choice for the complex control system required by this problem. With the exception of a programmable function generator capable of providing the necessary timing and synchronizing signals, all of the necessary CAMAC modules were commercially available. It 1 s the purpose of this report to describe our development of such a CAMAC programmable function generatur.

\section{DESCRIPTION OF FUNCTION GENERATOR}

\section{Overview}

A block diagram of the programmable function generator is shown in DWG Q-5747-1* and photographs of the completed module are shown in Fig. 1. The CAMAC functions to which it responds are given in Table 1. As may be seen in the block diagram, the module has been designed to store and independently execute a program (CAMAC loaded and controlled) to drive the digital-to-analog converter (DAC) which generates a $-10 \mathrm{~V}$ to $+10 \mathrm{~V}$ analog signa1. The module has a $\mathrm{lK} \times 12$-bit random access memory (RAM) and an indepentent program counter (PC) which are used to store and execute the program. An on-board $1 \mathrm{MHz}$ clock is used to shift the stored memory contents (analog wavefuim) out to the 12-bit DAC. The rinsk frequency may be divided by a factor which ranges from 1 to $2^{18}$ and which may be loaded from the dataway. In addition, there are two independent syuchronization signals, each of whose frequency may also be loaded from the dataway into separate registers. Lüic has also been piovided to control and select various LAM (interrupt) signals. A variety of status and control LED indicators have been provided on the front panel as may be seen in Fig. 1(a).

* The schematic drawings for the function generator are found as foldouts in Appendix A. 

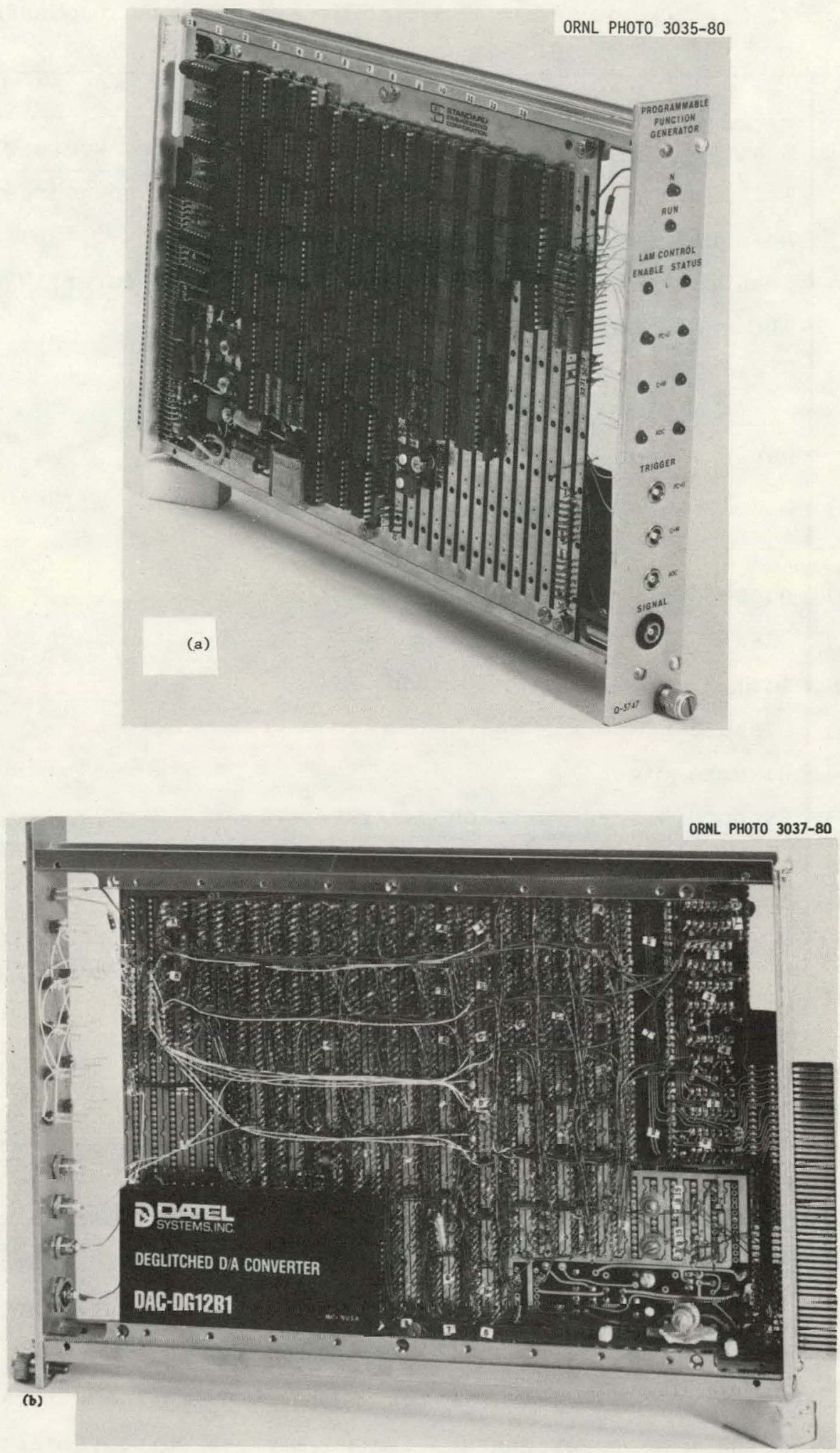

Fig. 1. The ORNL Q-5747 programmable function generator. (a) Front view, (b) wirewrap side. 
Table 1. Programmable Function Generator CAMAC Commands

\begin{tabular}{|c|c|}
\hline Function & Operation \\
\hline $\mathrm{F}(0) \mathrm{A}(0)$ & Read memory; advance memory address; $Q=1$ on address overflow \\
\hline $\mathrm{F}(16) \mathrm{A}(0)$ & Write memory; advance memory address; $Q=1$ on address overflow \\
\hline $\mathrm{F}(17) \mathrm{A}(0)$ & Load clock frequency register (W1-W18) \\
\hline $\mathrm{F}(17) \mathrm{A}(1)$ & $\begin{array}{l}\text { Load trigger registers; (W1-W8 for } C=M \text { register; W9-W12 for } \\
A D C \text { register) }\end{array}$ \\
\hline $\mathrm{F}(10) \mathrm{A}(1)$ & Clear ADC $(C=T)$ LAM \\
\hline $\mathrm{F}(10) \mathrm{A}(2)$ & C1ear PCOVFL $(P C=0)$ LAM \\
\hline $\mathrm{F}(10) \mathrm{A}(3)$ & Clear $\mathrm{C}=\mathrm{M}$ LAM \\
\hline $\mathrm{F}(11) \mathrm{A}(0)$ & $\begin{array}{l}\text { Module zero; clear PC; disable clock; disable all LAMs; clear } \\
\text { a11 LAMs; clear all registers and latches. }\end{array}$ \\
\hline $\mathrm{F}(24) \mathrm{A}(0)$ & Disable LAM \\
\hline $\mathrm{F}(24) \mathrm{A}(1)$ & Disable ADC trigger $(\mathrm{C}=\mathrm{T})$ LAM \\
\hline $\mathrm{F}(24) \mathrm{A}(2)$ & Disable PCOVFL $(\mathrm{PC}=0)$ LAM \\
\hline $\mathrm{F}(24) \mathrm{A}(3)$ & Disable $\mathrm{C}=\mathrm{M}$ LAM \\
\hline $\mathrm{F}(24) \mathrm{A}(4)$ & Disable clock \\
\hline $\mathrm{F}(25) \mathrm{A}(0)$ & Execute; start function generator \\
\hline $\mathrm{F}(25) \mathrm{A}(1)$ & Advance PC \\
\hline $\mathrm{F}(26) \mathrm{A}(0)$ & Enable LAM \\
\hline $\mathrm{F}(26) \mathrm{A}(1)$ & Enable ADC trigger $(C=T)$ LAM \\
\hline $\mathrm{F}(26) \mathrm{A}(2)$ & Enable PCOVFL $(\mathrm{PC}=0)$ LAM \\
\hline $\mathrm{F}(26) \mathrm{A}(3)$ & Enable $C=M$ LAM \\
\hline $\mathrm{z}$ & Same as $F(11) A(0)$ \\
\hline $\mathrm{C}$ & Same as $\mathrm{F}(11) \mathrm{A}(0)$ \\
\hline
\end{tabular}

The various sections and their operation are described in the following paragraphs. The entire module has been constructed on a standard Engineering Corp. WW-3 prututype wirewrap card. Low power Schnttky (LS) TTL logic has been used throughout. (An exception is the CD4001 CMOS chip used in the clock circuit.) This was especially important because with standard TTL the high power consumption of several chips (notably the 'LS193 counters) made the power consumption of the module exceed the CAMAC specification of $2 \mathrm{~A}$ on the $+6 \mathrm{~V}$ power supply. 
Memory and Program Counter

The Memory is a block of $1024 \times 12$ bits constructed from twelve Advanced Micro Devices AM9102 random access memory chips* (11A-13B) The AM9102 chips are 1024 bit static N-channel MOS devices organized as $1024 \times 1$ and have a power saving standby mode. Their access time is $650 \mathrm{~ns}$. The RAMs are bused together on a 12-bit address bus as shown on Q5747-2. The memory is written into from the dataway (W1-W12) with $[F(16) A(0)]$; write memory and increment program counter. The write lines W1-W12 are enabled to the "data-in" leads of the RAMs by WRT. This is a 300 ns negative pulse generated by the retriggerable, resettable monostable multivibrator in $10 \mathrm{D}$ when triggered by $[\mathrm{F}(16) \mathrm{A}(0)]$. WRT enables the tristate hex bus drivers ('LS367) in 7G and $8 G$ and is also bused to the write enable of the RAM. The memory address (A0-A9) is generated in the program counter as discussed in the next paragraph. The data out (D01-D012) of the RAM is connected directly to the DAC input buffer. (DO1 LSB) and also to the 'LS367 hex bus drivers ( $8 \mathrm{E}$ and $8 F$ ) on $Q 5747-3$. These drivers are enabled by $[\mathrm{F}(0) \mathrm{A}(0)]$ which gates D01-D012 onto R1-R12 of the dataway. Thus, data may be written from the dataway into memory, read from memory to the DAC, and read from memory onto the dataway.

The program counter (PC) generates the address for the memory. The $\mathrm{PC}$ is an incremental up counter built around LS193's (9E, 10A, 10B) as shown on Q5747-3. There are four conditions which may increment the PC: write data $\left[\mathrm{NF}(16) \mathrm{A}(0) \mathrm{S} 2^{-}\right]$; read data $\left[\mathrm{NF}(0) \mathrm{A}(0) \mathrm{S} 2^{-}\right]$, advance $\mathrm{PC}$ $\left[\mathrm{NF}(25) \mathrm{A}(1) \mathrm{S}^{-}\right]$, and $\overline{\mathrm{CLK}^{-}}$. (The latter is present only when the module is in the execute mode.) These four signals are ORed since any one should cause the memory address to be incremented. There are two conditions which can clear (zero) the PC. These are module zero [MZ; $\mathrm{F}(11) \mathrm{A}(0)$ ] (on $\mathrm{Q} 5747-2$ ) and execute [EXE; $\mathrm{F}(25)(\mathrm{A0})$ ]. MZ clears all registers including the $\mathrm{PC}$ and the memory. EXE clears the $\mathrm{PC}$ in order to. force the memory to start at location zero when the function generator is started. This is accomplished by using the leading edge of EXE to clear the PC and the trailing edge to set the execute flag (see Q-5747-2).

\footnotetext{
${ }^{*}$ AM9102 are plug compatible with Inte1 2102, Signetics 2602, Intersil IM7552, and Mostek 4102.
} 
During operation of the module it is necessary to know when the memory goes through a full cycle and to have a signal avallable for external devices. In addition, if enabled, a LAM may be generated. The end of cycle is detected by NANDing the carry of the second PC counter with the two high order bits of the third counter. This signal presets the overflow flag and is gated onto the $Q$ line of the dataway with $N^{\prime}$. The overflow flag is cleared with the next $\mathrm{S} 2^{\prime}$. With this procedure, it is possible to either read or write the entire memory ( 1024 words) in the Qstop controlled block transfer mode. 8

\section{Digital-to-Analog Converter}

The digital-to-analog converter is a model DAC-DG12Bl from DatelIntersil, Inc. The unit is a 12-bit DAC with a fast voltage output and is organized in three sections. These are: a 12-bit strobed digital input buffer, an ultra-fast 12-bit current conversion block with a deglitched switch and a stable Zener reference, and a fast-response operational amplifier. The DAC and associated $\log 1 \mathrm{c}$ are shown on Q-5747-2. The manufacturers specifications are given in Appendix $B$.

'l'he required $+1 b$ and $-1 b V$ supplies are derived trom $\mid 81 b$ and $|y| b$ voltage regulators, respectively, which operate of $f$ the CAMAC $+24 \mathrm{~V}$ and $-24 \mathrm{~V}$ supplies. The +VCC logic supply which used to power the DAC input register is drawn from the $+5 \mathrm{~V}$ regulator used to power the TTL logic. The DAC may be connected for $0-10 \mathrm{~V},-5$ to $+5 \mathrm{~V}$, or -10 to $+10 \mathrm{~V}$ output peak to peak. We have implemented the latter by using pins 31 and 32 for the DAC output. The analog ground is connected to pins 29 and 30 . Care has been taken to keep the analog ground separate from the digital ground to ensure maximum isolation and noise immunity for the output signal. External trim pots $(100 \Omega)$ are provided as shown for the gain and bipolar offset adjustments. The gain adjustment assures a symmetrical plus and minus swing. The bipolar offset adjustment is to ensure that the digital code at the input register is calibrated to give the proper output. The 12-bit input register is connected to the twelve data bits from RAM D01-D012. The data are strobed into the register with STB' which is generated as shown on Q-5747-3. The leading edge of CLK' initiates a 650 ns 
delay generated by the monostable multivibrator in 10C (on Q-5747-3). This delay is to ensure data DO1-D012 are valid to the DAC before actually generating the strobe pulse (RAM worst case access $=650 \mathrm{~ns}$ ). The $80 \mathrm{~ns}$ pulse produced at the end of the delay is the actual strobe. Note that STB' is locked out during a memory read to the dataway [F(0)A(0)] to ensure that the DAC is isolated from the data lines during a read operation.

\section{Programmable Frequency Clock}

The basic clock frequency of $1 \mathrm{MHz}$ is provided by a crystal oscillator and a CMOS pulse-shaping circuit as shown in Q-5747-2. In order to ensure that the clock pulses are not clipped on either STOP or START, a 74120 pulse synchronizer is used to gate the clock signal. The clock is gated to three separate counters by a START flag which is derived from the EXE command $[\mathrm{F}(25) \mathrm{A}(0)]$ through the flip-flop in $6 \mathrm{~A}$. The flag is clocked high enabling the synchronizer when EXE is given. Note that a memory read $[\mathrm{F}(0) \mathrm{A}(0)]$, memory write $[\mathrm{F}(16) \mathrm{A}(0)]$, disable clock $[F(24) A(4)]$ and master clear (MZ) all clear the flag to ensure that the clock is disabled during these operations. This is important since accidentally operating the PC with CLK and Read or Write simultaneously would be catastrophic. This clock signal (CLK) is the base frequency for the programmable up counters. The preset number (binary divisor) is loaded in 2's complement and latched from the Dataway W1-W18 lines via the three hex $D$ flip-flops $(7 \mathrm{~A}-7 \mathrm{C})$ which connect to the counter preset lines. These latches are cleared with $\mathrm{MZ}$ and loaded with [F(17) A(0)S1'] (Load Clock Frequency register). It is important to note that the data loaded in the latches are then loaded into the counters at $\left[F(17) \mathrm{A}(0) \mathrm{S} 2^{\prime}\right]$. In this way, when the module is started the first CLK' pulse will appear at the correct time following EXE. Otherwise, the first CLK' pulse would appear after $2^{18}$ pulses or $262 \mathrm{~ms}$. The counters are used as modulo-N divider counters with the [F(17) $\left.\mathrm{A}(0) \mathrm{S} 1^{\prime}\right]$ data used as an offset. The last carry out is used to edge trigger a $D$ flip-flop producing CLK' (programmed clock) on the $Q$ output. CLK' is also used to reload the latched preset number to the counters. The next CLK pulse will clear the flip-flop and the entire cycle will repeat. 
The crystal oscillator frequency ( $1 \mathrm{MHz}$ ) can be divided by any binary number between 1 and $2^{18}$. Since the PC always counts through 1024 locations, the frequency range of the function generator is from 0.003725 to $976.6 \mathrm{~Hz} .{ }^{*}$ of course, if less resolution is required in the output waveform, more than one period of the desired function could be loaded into the memory in order to increase the output frequency.

\section{Programmable Synchronization Registers}

Two additional registers were implemented to allow programmed control of data acquisition. One signal is used to strobe a pair of CAMAC analog-to-digital converters (ADCs) which are connected to the sample displacement linear variable differential transformer (LVDT) signal conditioner and the load cell signal conditioner. In order to obtain accurate stress-strain relationships it is necessary to measure numerous points (e.g., 128) in each function generator cycle. Similarly, in order to synchronize the diffraction pattern data acquisition system with the function generator output, it is necessary at various preprogrammed times to signal either a Signetics $8 \times 300$ microcontroller 1,9 or the Time Correlator of the new LASL-ORNL fast digital data acquisition system 10 that they must change the origin of the data acquisition array. The $\mathrm{ADC}$ and Time Correlator triggers are strobe pulses, while the $8 \times 300$ signal is a latched handshaking signal which is cleared on $1 y$

\footnotetext{
*With an 18 bit divisor and a $1 \mathrm{MII}$ liuch, Lhe high lieyuency repel1tion races have little selectability. 'lhe available frequencies are $976.6 * 2^{-n}(n=0,1,2, \ldots 262,144)$ or $976.6,488.2,325.5,244.1,195.3$, $162.8,139.5 \ldots$. For the present application, where we are concerned with the very low frequency region, such limitations are unimportant. However, in other applications where greater selectability at higher frequencies is necessary, two possibilities exist. If the present dynamic range is satisfactory, one must merely replace the crystal oscillator with one of higher frequency. On the other hand, if a greater dynamic range is required, it is straightforward to provide a 24-bit divisor by adding an 'LS193 counter, an 'LS174 data latch, and a hex 'LSO4 inverter.
} 
on acknowledgment by the $8 \times 300$. These two signals, labeled $C=T$ ( $A D C$ trigger) and $C=M$ (memory map) are generated in a manner similar to CLK'.

The two registers use the divided clock (CLK') as their base frequency. Although sharing the same base frequency the two registers are completely independent. They are loaded simultaneously with their preset numbers (in 2's complement); Wl-W8 for $C=M$ and W9-W.12 for $C .=T$ $(7 D-7 E)$. The preset number on $W 1-W 12$ is latched in the hex $D$ flip-flops with [F(17)A(1)S1'] (Load Trigger Registers). The registers are connected to the preset of 'LS193 up/down binary counters which are used as modulo-N dividers. The data are loaded into the counters with $\left[\mathrm{F}(17)(\mathrm{Al}) \mathrm{S}^{-}\right]$as with the programmable frequency clock in order to ensure proper synchronization with EXE. The carry out of $9 \mathrm{C}$ is used to edge trigger the $D$ flip-flop in $14 \mathrm{~A}$ which in turn uses $\bar{Q}$ to (a) reload the counters $(9 A-9 C)$ to preset values, (b) to produce $\overline{C=M}$ for the flip-flop at $6 \mathrm{~A}$ and. (c) to provide the " 1 " for next edge trigger. The next CLK' (beginning of next cycle) will clear the $\overline{C=M}$ flip-flop (14A). The $\overline{C=M}$ signal is also latched and sent to the status input word of the microprocessor communication module ${ }^{9}$ ( so it can be used to change the memory map). The flip-flop is cleared when the microprocessor responds with a status acknowledgment. The $\bar{C}=\mathrm{T}$ signal (14A and 10D) is generated in the same manner as $\overline{C=M}$ utilizing the logic shown on Q5747-2. The $\overline{C=T}$ is used to trigger an adjustable (150-250 ns) monostable multivibrator in $10 \mathrm{D}$ which produces the negative asserted pulse which goes to the ADC trigger.

\section{LAM Control Logic}

It is often necessary to generate computer interrupts via the CAMAC LAM (look-at-me) signals when certain events occur. In the present module, depending on experimental conditions, it may be desirable to generate a LAM: (1) when $P C=0$, (2) when $C=M$, or (3) when $C=T$ (1.e., when the address counter overflows, when the ADC trigger is set, or when the microprocessor communication module or Time Correlator trigger is set).

The logic on Q5747-3 performs this task. First, the LAM line itself may be enabled with an $\left[\mathrm{F}(26) \mathrm{A}(0) \mathrm{Sl}^{\prime}\right]$ or may be disabled with an 
$[\mathrm{F}(24) \mathrm{A}(0) \mathrm{Sl}$ ' + $\mathrm{MZ}]$. The enable/disable is controlled by an 'LS74 D flip-flop. The three signals which can generate a LAM are handled similarly. They may all be selectively enabled or disabled, and the actual LAM may be selectively cleared (allowing priority servicing). The enable is implemented with [F(26)A(n)Sl'], disable is [F(24)A(n)S1'] and clear is $\left[F(10) A(n) S l^{\prime}\right]$. The three subaddresses are organized as follows: $\mathrm{A}(1)$ - $\mathrm{ADC}$ trigger; $\mathrm{A}(2)-\mathrm{PC}=0$; and $\mathrm{A}(3)-\mathrm{C}=\mathrm{M}$ trigger. The logic is organized similarly for all three with the left bank of $D$ flip-flops used as an enable/disable latch which opens or closes the appropriate gate leading to the LAM logic. The actual signals are latched in the right bank of $D$ flip-flops and remain there until they are selectively cleared. Front panel LEDs indicate which LAM is enabled and whether or not a LAM is present. The LAM status is displayed until cleared by $\left[F(10) A(n) S l^{\prime}\right]$.

\section{SOFTWARE}

A function generator driver program called FGEN has been coded in top-down structured FORTRAN 11 using the SFORTRAN precompiler.12 A source listing is given in Appendix C. This program contains six sections :

(1) a function form generator,

(2) write mpmnry,

(3) verify memory,

(4) set frequency registers,

(b) LAM enables, and

(6) run/stop.

Al1 CAMAC communication with the module is via the standard CAMAC subroutines CFSA, CSSA, and CVSA as defined in the CAMAC tutorlal articles $^{8}$ and as implemented by King and Hendricks 13 for the ORNL ModComp computers. The various commands to which the program responds are sumnarized in Table 2. The program response to each command guides the user as to what information is required and the necessary input format. Although. this code currently generates sine, triangular or 
Table 2. Summary of FGEN Commands

\begin{tabular}{|c|c|}
\hline COMMAND $^{*}$ & Purpose \\
\hline & . \\
\hline EXIT & Exit from program. \\
\hline HALT & Stop function generator. \\
\hline LAM & Enable, disable and clear LAMs. \\
\hline PARAM & Enter execution parameters (frequency and trigger registers). \\
\hline$\underline{\text { RUN }}$ & Start function generator in execution. \\
\hline VERIFY & Read memory and compare with WRITE command. \\
\hline WRITE & Write desired function curve into memory. \\
\hline
\end{tabular}

* The command may be abbreviated to the underlined characters. All commands must be terminated by a carriage return.

square waves, clearly any form of input can be easily coded. A typical operating sequence which loads and verifies the memory, loads the counter registers, and then starts the function generator in execution is shown in Example 1. It is important to note that once the generator is started in execution, FGEN is no longer required to remain in core. Thus, core can be utilized by other programs once the unit is running.

\section{Acknowledgments}

The authors are indebted to R. T. Roseberry and J. W. Woody, Jr. for their continued interest and encouragement and for their valuable suggestions, to E. Madden for comments on the manuscript, and to F. Sims for his expertise in wirewrapping and assembling the module. 


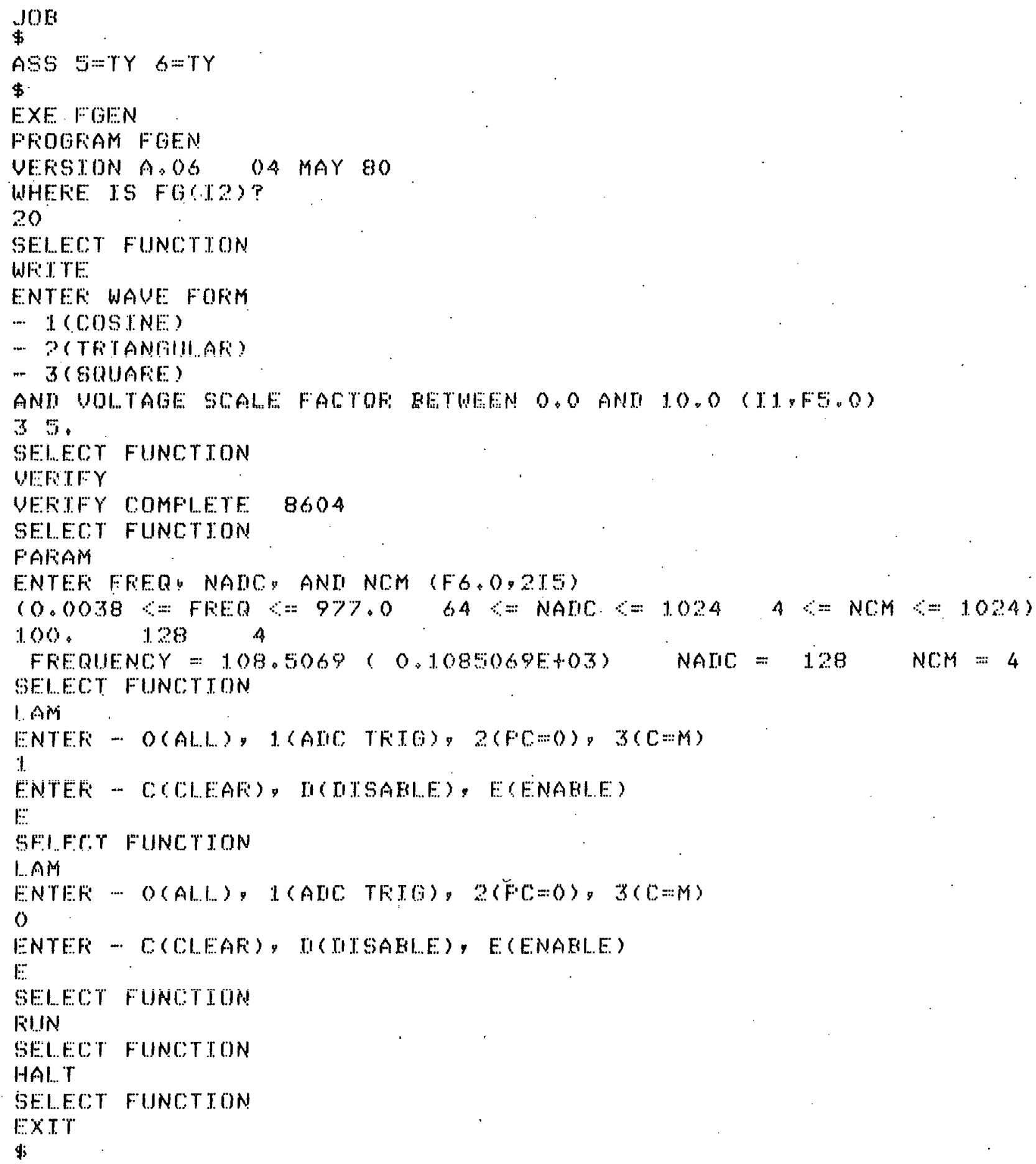




\section{REFERENCES}

1. R. W. Hendricks, J. Appl. Cryst. 11, 15-30 (1978).

2. W. C. Koehler and R. W. Hendricks, "Construction and Operation of a National User-Oriented Small-Angle Neutron Scattering Facility at the Oak Ridge National Laboratory," a proposal accepted for funding by the National Science Foundation, Grant No. DMR-7724458 (1977).

3. W. C. Koehler and R. W: Hendricks, J. App1. Phys. 50, 1951 (1979).

4. J. M. Schultz, J. S. Lin; and R. W. Hendricks, J. Appl. Cryst. 11, 551-557 (1978).

5. R.W. Hendricks, "Design and Construction of a Specimen Holder and Control System for Dynamic $X$-Ray and Neutron Small-Angle Scattering Studies of the Plastic Deformation of Polymers," a proposal accepted for funding by the National Science Foundation (February 1979).

6. R. W. Hendricks and S. Suehiro (to be published).

7. P. A. Seeger, A Fast-Response CAMAC Crate Controller, Los Alamos Scientific Laboratory Report, LASL-6 $605-M$, Los Alamos, New Mexico, (December 1976).

8. CAMAC Tutorial Articles, US NIM Committee, Energy Research and Development Report TID-26618 (October 1976).

9. G. W. Turner and R. W. Hendricks, Nucl. Instrum. Meth. 169, 373-380 (1980).

10. R. W. Hendricks, P. A. Seeger, J. W. Scheer, and S. Suehiro, The LASL-ORNL Fast Digita1 Data Acquisition System, Oak Ridge National

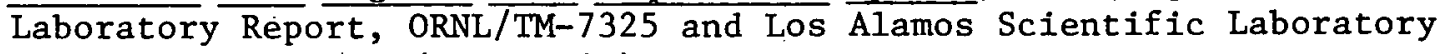
Report LASL-8260-M (June 1980).

11. E. Yourdon, Techniques of Program Structure and Design, Prentice-Ha11, Englewood Cliffs, New Jersey, 1975 .

12. SFORTRAN was developed by Lars G. Mossberg of Volvo Flysmotor, A.B., Trollhattan, Sweden, and is distributed in the United States by Software Consulting Services, 901 Whittier Drive, Allentown, PA 18103.

13. S. P. King and R. W. Hendricks, The ORNL 10-m Small-Angle X-Ray Scattering Camera. 8. CAMAC Software, Oak Ridge National Laboratory Report ORNL/TM-6342 V8 (in preparation). 
$\Lambda$ PPENDIX A

Circuit Diagrams

ORNL Model Q-5747 Programmable Function Generator 


\section{PAGES 15 to 16 WERE INTENTIONALLY LEFT BLANK}




\section{THIS PAGE}

\section{WAS INTENTIONALLY \\ LEFT BLANK}




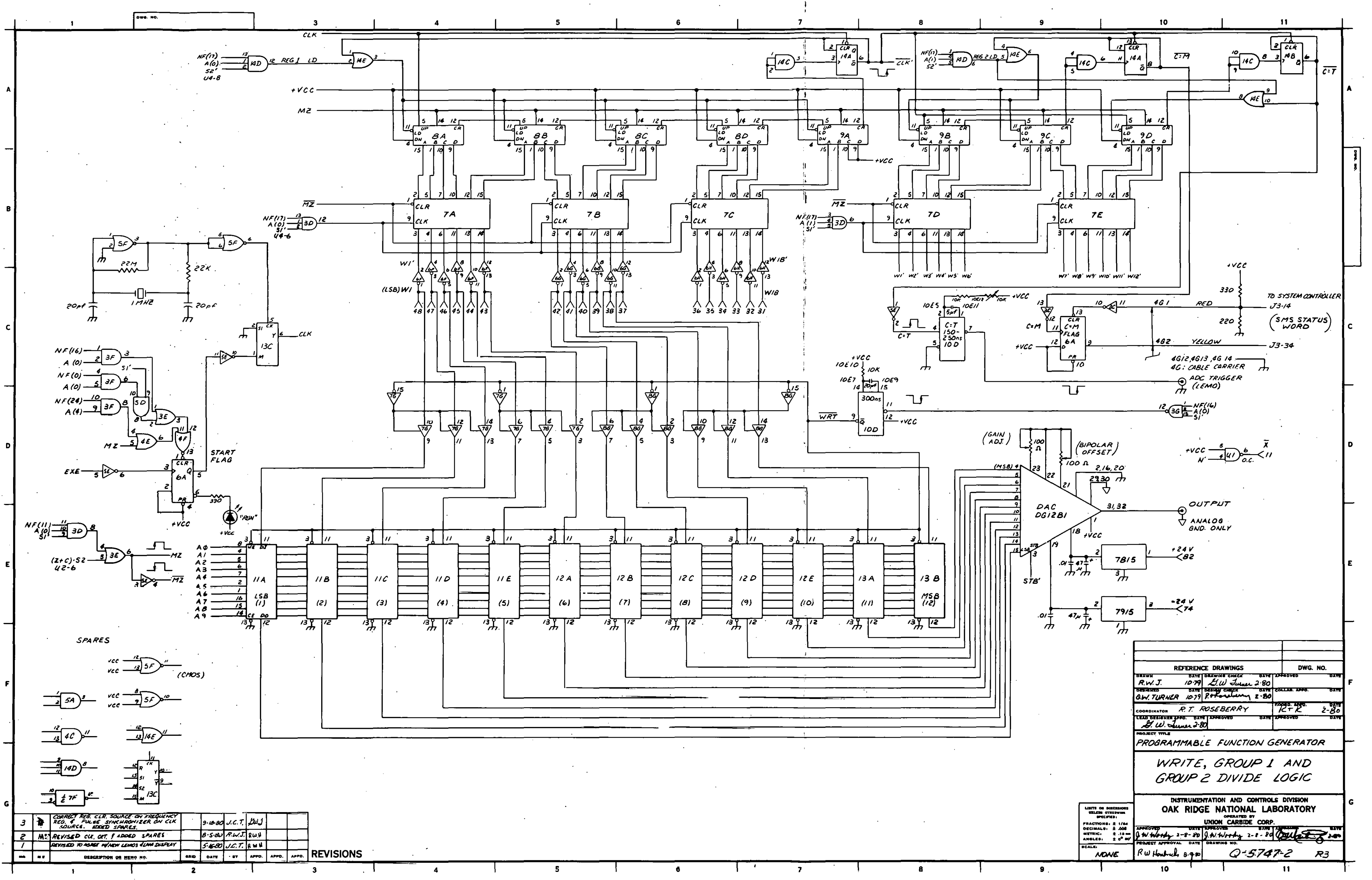




\section{THIS PAGE WAS INTENTIONALLY LEFT BLANK}


THIS PAGE

WAS INTENTIONALLY

LEFT BLANK 


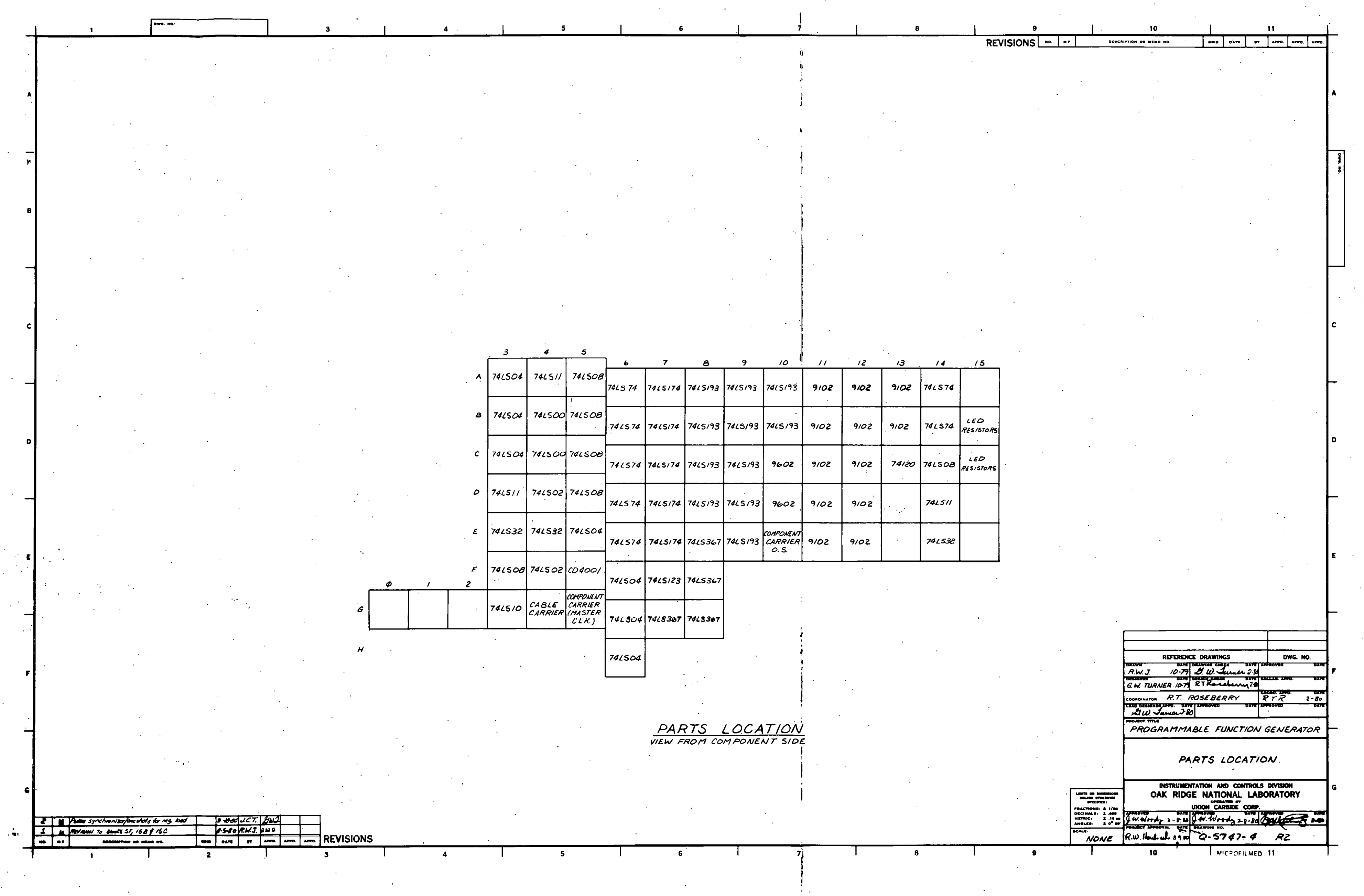


THIS PAGE

WAS INTENTIONALLY

LEFT BLANK 
APPENDIX B

Manufacturers! Specifications *

DATEL - INTERSIL MODEL DAC-DG12B1

Digital-to-Analog Converter

*Taken with permission from DATEL "Modules for Data Conversion" handbook. 


\section{THIS PAGE WAS INTENTIONALLY LEFT BLANK}




\section{FAST 12-BIT DEGLITCHED DAC}

\section{MODEL DAC-DG12B}

\section{FEATURES}

- \pm 2 LSB Max. Glitch

- 600 nsec. Settling Time

- Up to 2.5 MHz Update Rate

- 12 Bit Resolution

- Self-Contained Module

GENERAL DESCRIPTION

Model DAC-DG12B is a deglitched 12 bit $D / A$ converter with a fast voltage out- ${ }^{-}$ put. The maximum output glitch amplitude is \pm 2 LSB's while settling time for a 10 volt output change is $600 \mathrm{nsec}$. to 1 LSB. For a 10 volt change to $1 \%$ the settling time is $250 \mathrm{nsec}$. and for smalt output changes it is only 400 nsec., permitting update rates as fast as $2.5 \mathrm{MHz}$. The unique circuit design of the DACDG $12 \mathrm{~B}$ realizes both small size and low price at the same time. Unlike other deglitched DAC's which are comprised of several inter-connected modules mounted on a circuit card. the DAC DG12B is completely self-contained in a compact $4 \times 2 \times 0.4$ inch $(102 \times 51 \times$ $10 \mathrm{~mm}$ ) module. It consists of several optimized circuit functions: digital input register. ultra-fast 12-bit current DAC. stable Zener voltage reference, fast deglitching switch. and a fast output operational amplifier.

The DACDG12B has three voltage output ranges determined by external pin connection: 0 to $-10 \mathrm{~V} \pm 5 \mathrm{~V}$ and $\pm 10 \mathrm{~V}$ Output current is $\pm 10 \mathrm{~mA}$ with output short circuit protection; for higher output current requirements an external rusrent booster amolifier mav be connected inside the feedback loop of the output amplifier. There are two input coding options: complementary bina$\mathrm{ry} / \mathrm{complementary}$ offset binary or complementary two's complement.

The DACDG12B is an ideal device for fast CRT display applications and for other test and measurement applications where monotonic output changes are required.
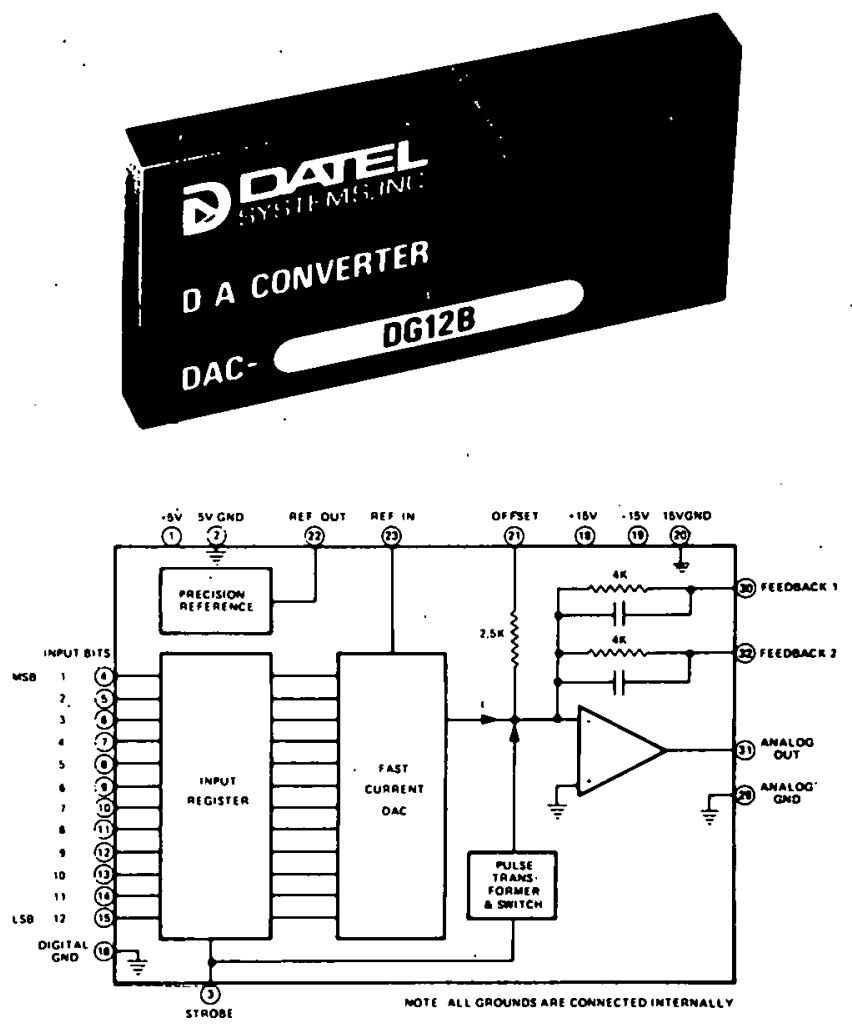

MECHANICAL DIMENSIONS - INCHES (MM)
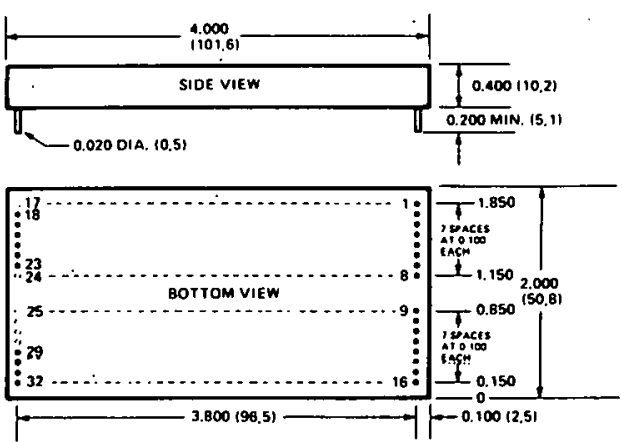

INPUT/OUTPUT CONNECTIONS

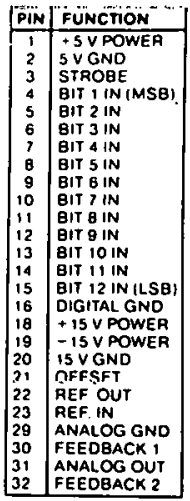


SPECIFICATIONS. DAC-DG 128

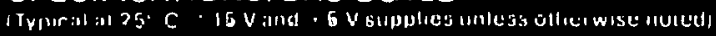

\section{INPUTS}

Resolution.

Coding, unipoler.

Input Logic Level, bit ON ("0")

12 bits

Complementary Binary

Complementary Otf'set Binary '

Complementary Two's Comp."

ov to +0.8 V

Input Logle Level, bit OFF ("1") .

Logic Loading.

$+20 \mathrm{~V}$ to $+5.5 \mathrm{~V}$

1 TTL load

HI to LO transition causes

transfer of data trom

register to DAC.

Input Strobe Loading

\section{OUTPUTS}

Output Voltege, unipolor ${ }^{2}$

Output Voltage, bipolar ${ }^{3}$

Output Curront 8. C. protected.. $\pm 5 \mathrm{~V}_{1} \pm 10 \mathrm{~V}$

$\pm 2.0 \mathrm{~mA}$ typ., $=10 \mathrm{~mA} \mathrm{~min}$

Output Impedance. DC ....... $0.05 \mathrm{ohm}$

\section{PERFormance}

Linearity Error. .

Differentlal Nonlinearli. .......... $\quad \pm 1 / 2$ LSB $\max$

Zera Error, before trimming..... $\quad \pm 1 / 2$ LSB max.

Gain Tempco................ $\pm 35 \mathrm{ppm} /{ }^{\circ} \mathrm{C}$ max.

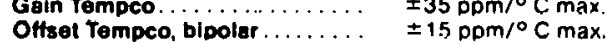

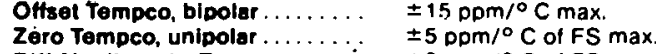

Dift. Nonlinearity Tempco....... \pm 2 ppm $1^{\circ} \mathrm{C}$ of FS

Monotonicity............... $0^{\circ} \mathrm{C}$ to $70^{\circ} \mathrm{C}$

Setiling TIme.

10V change to 1 LSB .........

Settling Time

20 V change to 1 LSB ........

Sottling TImo,

10 v change to $1 x \ldots \ldots \ldots$

20 v change to $1 \% \ldots \ldots \ldots$

Settling Time, \pm 4 LSB chanoe

Slew Rate.

Slow Rate..........

Glitch Amplitud

600 nsec. tyo. 700 nsec. max.

$1.0 \mu \mathrm{sec}$. typ. $1.2 \mu \mathrm{sec}$. max.

250 nsec. max.

550 nsec. max.

400 nser.

$50 \mathrm{~V} \mu \mathrm{sec}$.

\pm 1 LSB typ. \pm 2 LSB max.

$250 \mathrm{mV}$-nsec.

Power Supply Rejection........ $0.01 \% / \%$ supply

\section{POWER REQUIREMENT}

+15 VDC $\pm 0.5 \mathrm{~V} @ 50 \mathrm{~mA}$

-15 VDC $+0.6 V @ 35 \mathrm{~mA}$

+5 VDC $\pm 0.25 \vee$ @ $2.30 \mathrm{~mA}$

\section{PHYSICAL-ENVIRONMENTAL}

Operating Temperature Rिange .

Storage Temperature Renge...

Case Size.................

Oado Materlal..............

Plns..................

Wolghi

$0^{\circ} \mathrm{C}$ to $70^{\circ} \mathrm{C}$

$-55^{\circ} \mathrm{C} 10+125^{\circ} \mathrm{C}$

$4 \times 2 \times 0.4$ inches

(101.6 $\times 50.8 \times 10.2 \mathrm{~mm}$ )

Black Uiallyl Phthalate per

MIL-M-14

$0 \cap 20^{\prime \prime}$ round, gold plated.

$0.200 \mathrm{lg} . \mathrm{min}$

4 oz. max. $(114 \mathrm{~g})$

\section{NOTES}

1. Because the analog output is inverted, in the bipolar mode the complementary offset binary code is equivalent to offset binary and the complementary two's complement code is equivalent to two's complement. See Technical Note 4.

2. Has same logic levels as data inputs.

3. Determined by external pin connection.

4. Measured with $20 \mathrm{MHz}$ bandwidth oscilloscope at major carry (half scale) and at 7 transitions either side of major carry.

\section{TECHNICAL NOTES}

1. The sequence of operations inside the DACDG12B after the input strobe changes from $\mathrm{HI}$ to $\mathrm{LO}$ are:

a. the pulse transformer and switch are activated and turn ON

b. within 11 nanoseconds (typically) the data in the input register is transferred to the current DAC

c. during the next 19 nanoseconds (typically) the DAC out- . put current changes

d. after 30 nanoseconds (typically) from the strobe change the pulse transformer and switch are deactivated. turning OFF

e. the output amplifier begins to change to its new output value

2. A 5 nanosecond minimum setup time is required for the input data to be valid before the input strobe goes from $\mathrm{HI}$ to LO. The input strobe then should not go $\mathrm{Hl}$ again for at least 40 nanoseconds.

3. The maximum update rate for the DAC-DG12B is $25 \mathrm{MHz}$. bacod on the 400 nanosecond settling time for small outpuit changes ( \pm 4 L.SR s max). For $10 \mathrm{~V}$ changoo to $1 \%$ i of final value the maximum update rate is $4 \mathrm{MHz}$ and for $10 \mathrm{~V}$ changes to within 1 LSB of final value the maximum update changes to with
rate is $1.6 \mathrm{MHz}$.

4. From the coding tables it should be noted that each model of the DAC-DG12B has its coding defined in two ways when operating in bipolar mode. For the DACDG12B1 the complementary offset binary coding with inverted (negative) analog output is the same as offset binary coding with noninverted (positive) analog output except for an analuy shift of 1 LSB. The converter therefore can be externally caliof 1 LSB. The converter therefore can be externally cali-
brated for either code. For the DAC-DG $12 B 2$ the complementary two's complement coding with inverted (negative) analog output is the same as two's complement coding with noninverted (positive) análog uutput except for an analog shift of 1 LSB.

5. The DAC-DG12B is internally calibrated at zero for unipolar operation. with a zero error of $\pm 1 / 2$ LSB maximum. In many ajulicalions, ituefefore no exterñál zero adjustment is re quired. For exact calibration the external zero adjustment quired. For exact calibration the external zero adjustment
should be used. The DACDG 1282 operates in unipolar mode except that its input code is complementary binary with the MSB inverted.

6. For higher output current drive capability a wideband current honstar amplifior with unity doltage gain máy be ericlused irside the feedback loop of the output amplifier.

\section{ORDERING INFORMATION}

DAC-DG12B

\begin{tabular}{|c|}
\hline CODING \\
\hline $1=$ COMP. BINARY/COMP. OFFSET BINARY \\
$2=$ COMP. TWO'S COMPLEMENT
\end{tabular}

\section{PAICES (1-9)}

DAC-DG12B1 $\$ 275.00$

DAC-DG12B2 $\$ 875.00$

MATING SOCKETS: DILS-2

(2/MOOULE) AT 65.00/PAIF

TRIMMING POTENTIOMETERS:

TP100 (100 ohms). TP10K (10 K ohms) AT \$3.00 EACH

For extended temperature range operation, the following suffixes are added.to the model number. Consult factory for pricing. - EX $\quad-25^{\circ} \mathrm{C}$ to $+85^{\circ} \mathrm{C}$ operation

-EXX-HS $\quad-55^{\circ} \mathrm{C}$ to $+85^{\circ} \mathrm{C}$ operation with hermetically sealed semiconductor components

THE DAC-DG12B IS COVERED BY GSA CONTRACT 


\section{TIMING DIAGRAMS}

INTERNAL TIMING

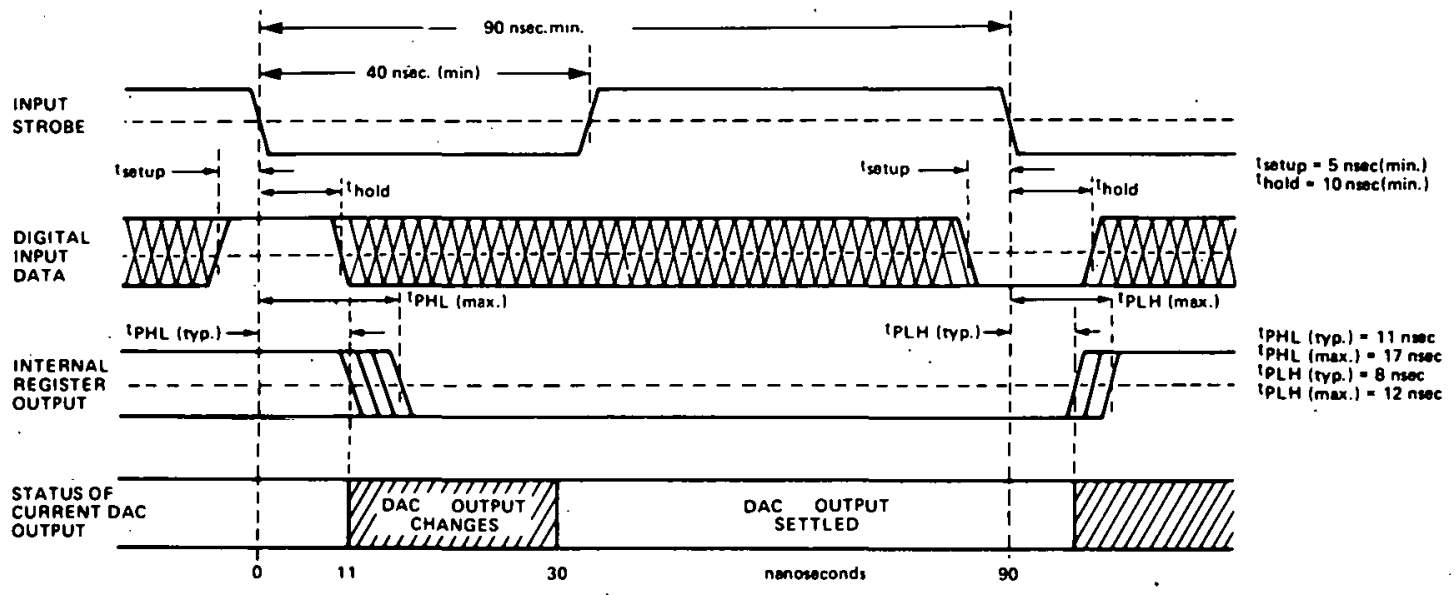

EXTERNAL TIMING

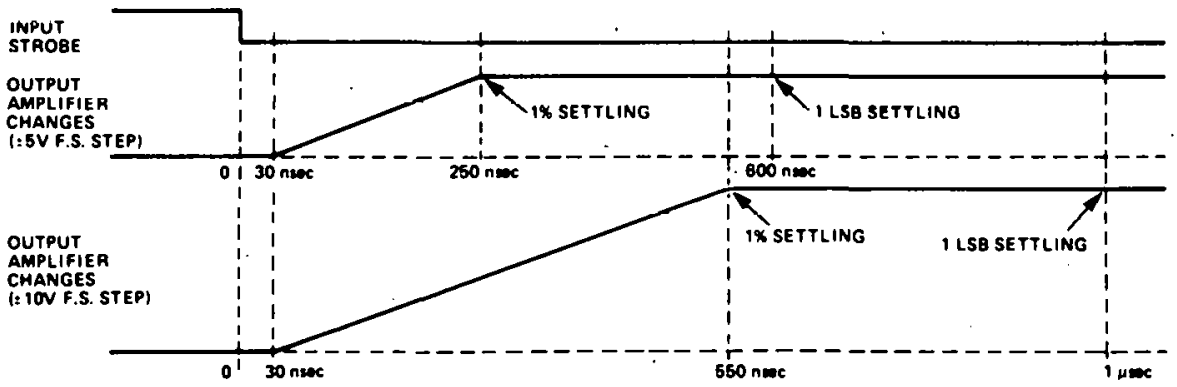

\section{CODING TABLES}

UNIPOLAR OPERATION

\begin{tabular}{|l|c|c|}
\hline \multirow{2}{*}{ SCALE } & VOLTAGE RANGE & DAC-DG1281 \\
\cline { 2 - 3 } & 0 TO-10V & COMP. BINAAY \\
\hline 0 & 00000 & 111111111111 \\
$0.1 \mathrm{LSB}$ & 00024 & 11111111110 \\
$-1 / \mathrm{FS}$ & 25000 & 10111111111 \\
$-1 / \mathrm{FS}$ & -50000 & 01111111111 \\
$-3 / \mathrm{FS}$ & -75000 & 00111111111 \\
$-\mathrm{FS}+1$ LSB & -99976 & 00000000000 \\
\hline
\end{tabular}

BIPOLAR OPERATION

\begin{tabular}{|c|c|c|c|c|c|c|}
\hline \multirow{2}{*}{ SCALE } & \multicolumn{2}{|c|}{ VOLTAGE RANGE } & \multicolumn{2}{|c|}{ DAC-DAC-DG 1281} & \multicolumn{2}{|c|}{ DAC-DO12B2 } \\
\hline & $\pm 5 \mathrm{~V}$ & $\pm 10 V$ & COMP. OFFS. BIN & OFFSET EINARY & COMP. 2's COMP. & 2'S COMPLEMENT \\
\hline $\begin{array}{l}+F S \\
+F 3 \cdot 1 \text { L3B } \\
0+1 \text { LSB } \\
0 \\
-F S+1 \text { LSB } \\
-F S\end{array}$ & $\begin{array}{l}+50000 v \\
149076 \\
+00024 \\
00000 \\
-49976 \\
-50000\end{array}$ & $\begin{array}{l}+100000 \mathrm{~V} \\
+90051 \\
+00049 \\
00000 \\
99951 \\
10000\end{array}$ & 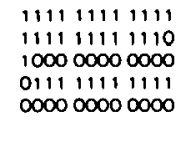 & $\begin{array}{l}111111111111111 \\
100000000001 \\
100000000000 \\
000000000001 \\
000000000000\end{array}$ & $\begin{array}{l}01111111111111 \\
0711111111110 \\
00000000 \text { uwe } \\
1111111111111 \\
100000000000\end{array}$ & $\begin{array}{l}011111111111 \\
00000000001 \\
000000000000 \\
100000000001 \\
10000000000\end{array}$ \\
\hline
\end{tabular}


CONNECTIONS AND CALIBRATION

CALIBRATION PROCEDURE

Select the desired output voltage range $(0$ to $-10 \mathrm{~V}$. $\pm 5 \mathrm{~V}$. or $\pm 10 \mathrm{~V})$ and make the connections shown in the diagrams below. To calibrate refer to the coding tables on the previous page.

UNIPOLAR OPERATION $(0$ TO - 10 V OUTPUT

1. Zero Adjustment: Set the digital inout code 1011111111 1111 and adjust the ZERO ADJ. potentiometer to give $0.0000 \mathrm{~V}$ output

2 Gain Adjustment: Sel ine digital input code to 00000000 0000 and adlust the GAIN ADJ Dotentiometer to give 9.9976 $\mathrm{V}$ output
BIPOLAR OPERATION ( $55 \mathrm{~V}$ OR $\pm 10 \mathrm{~V}$ OUTPUT)

Ottset Adjustment: Set the digital inout code to 01111111 1111 (comp. Offset bınary). 100000000000 (offset bınary). 111111111111 (comp iwo's complement) or 00000000 OOn . two s complement' and adjust the BIPOLAR OFFGET ADJ potentiometer to give $00000 \mathrm{~V}$ output

2 Goin Adjustment: Set the digital input code to 00000000 0000 icomp oftset binary'. 000000000001 ioffset binary). 100000000000 .comp iwo s complement). or 10000000 0001 : iwo s comolement ' and adjust the GAIN ADJ potentometer to give $49976 \mathrm{~V}$ output ifor $\pm 5 \mathrm{~V}$ range) or

$99951 \mathrm{~V}$ output for $=10 \mathrm{~V}$ rangel

3 Repual steus 1 ana 2 to recheck adjustments
UNIPOLAR OPERATION - NO ZERO ADJ.

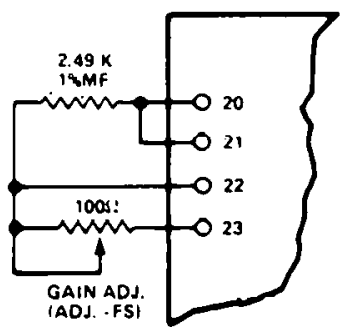

BIPOLAR OPEAATION

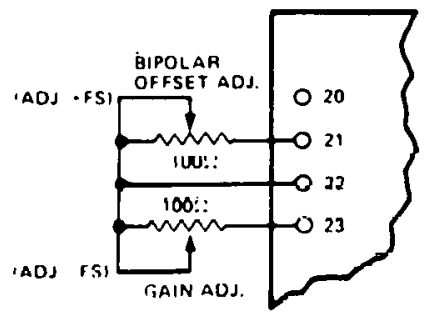

UNIPOLAR OPFA TIION - WITH ZERO ADJ.

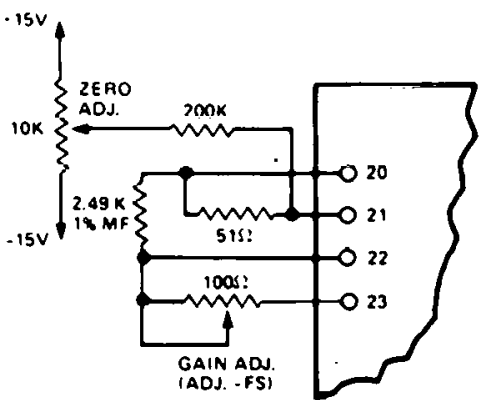

\section{OUTPUT CONNECTIONS}

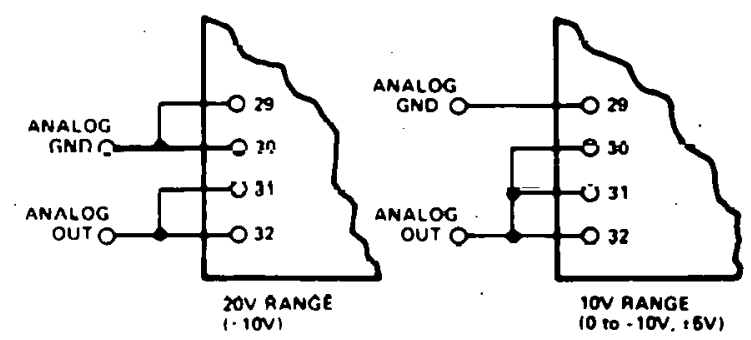




\section{APPENDIX C}

Program FGEN Source Listing 
32

THIS PAGE

WAS INTENTIONALLY

LEFT BLANK 


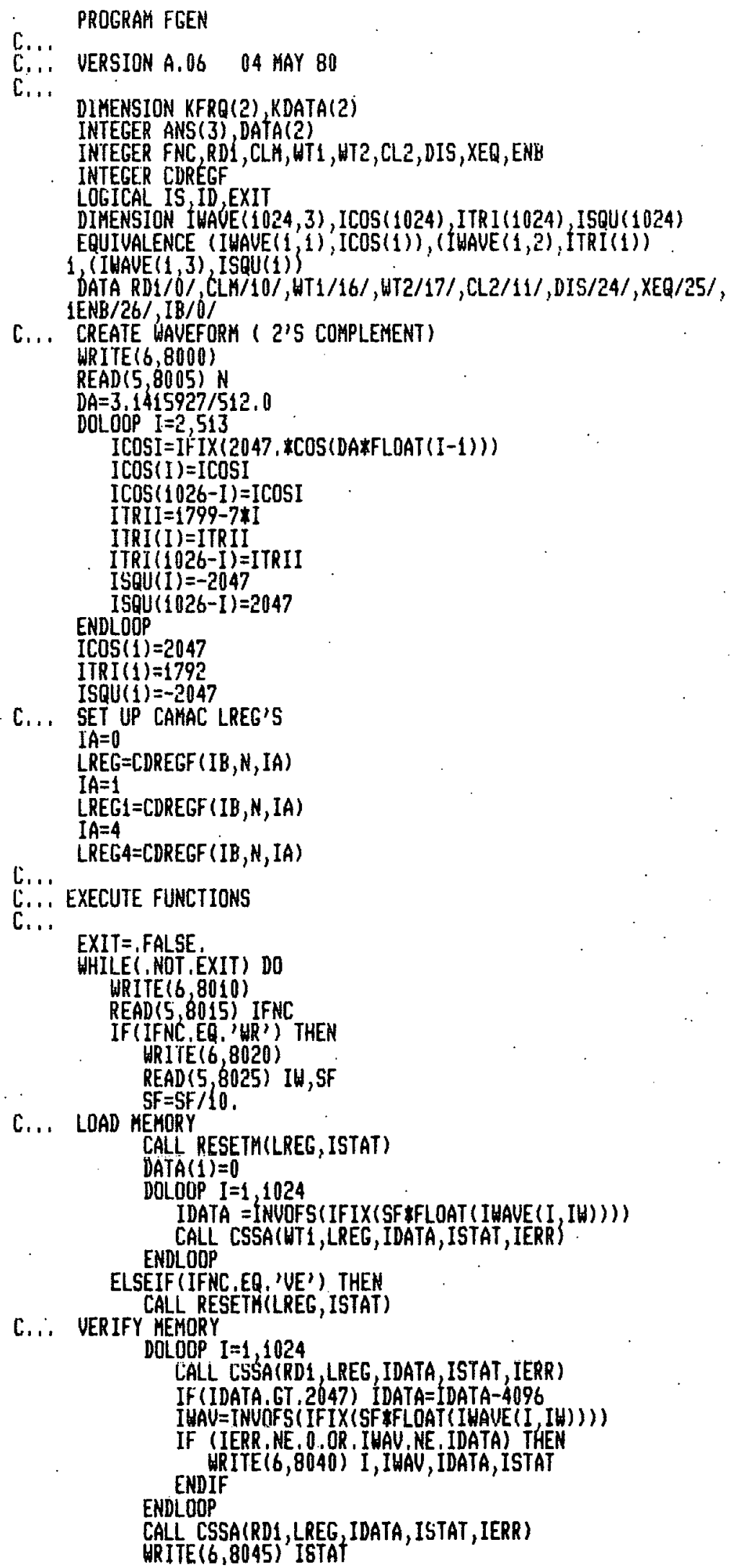




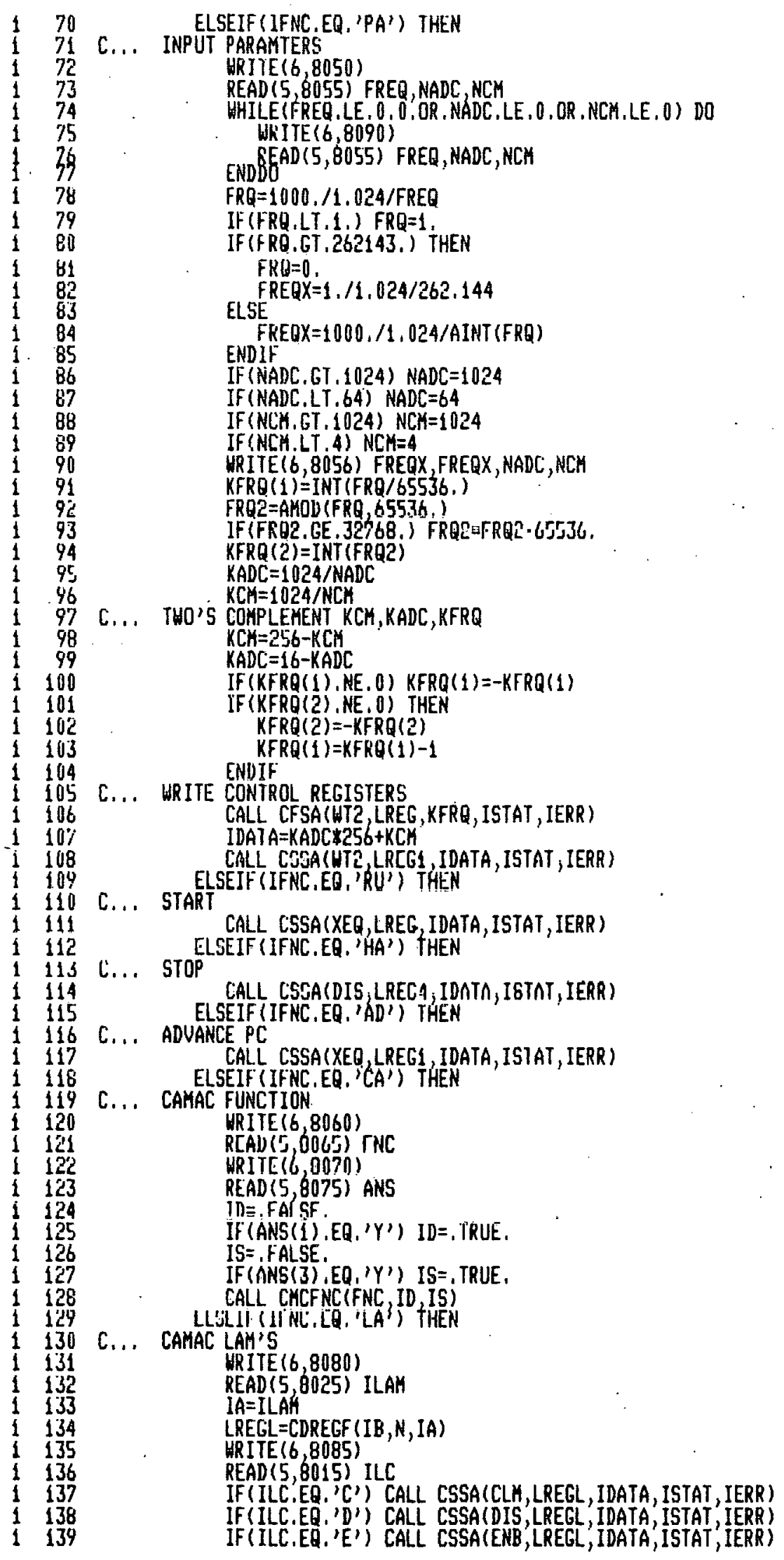




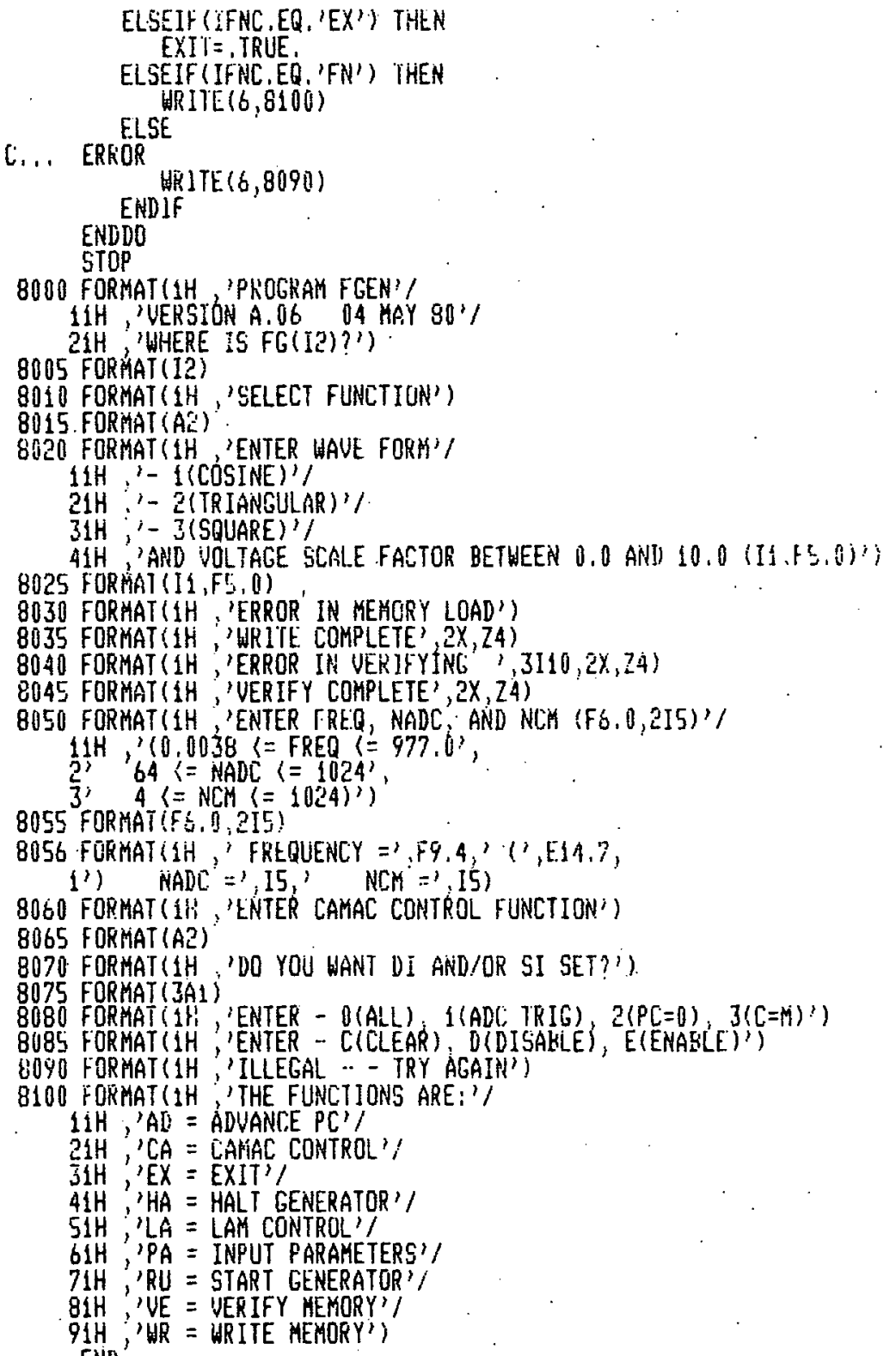

SUEROUTINE KESETM(LREG, ISTAT)

INTEGER DATA,CL2

$C L 2=11$

CALL CSSA(CL2,LREG, DATA, ISTAT, IERR)

IF (IFRR, NE, B) THEN

ENDIF

RITE $(6,8000)$ ISTAT

RETURN

8000 FORHAT ( 1 H,'RESET , $2 X, 24)$ END 


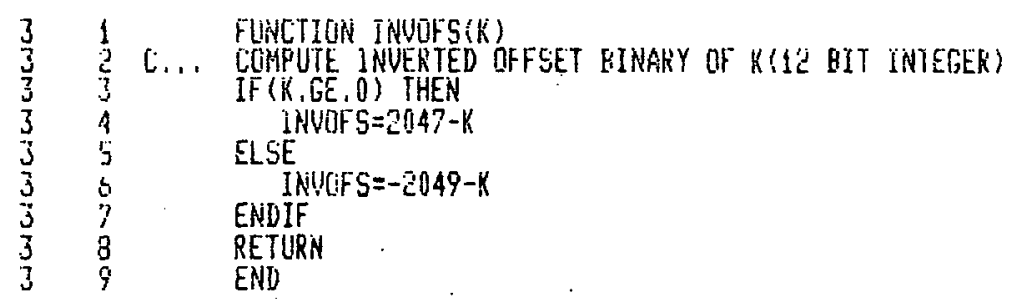


ORNL/TM-7363

INTERNAL DISTRIBUTION

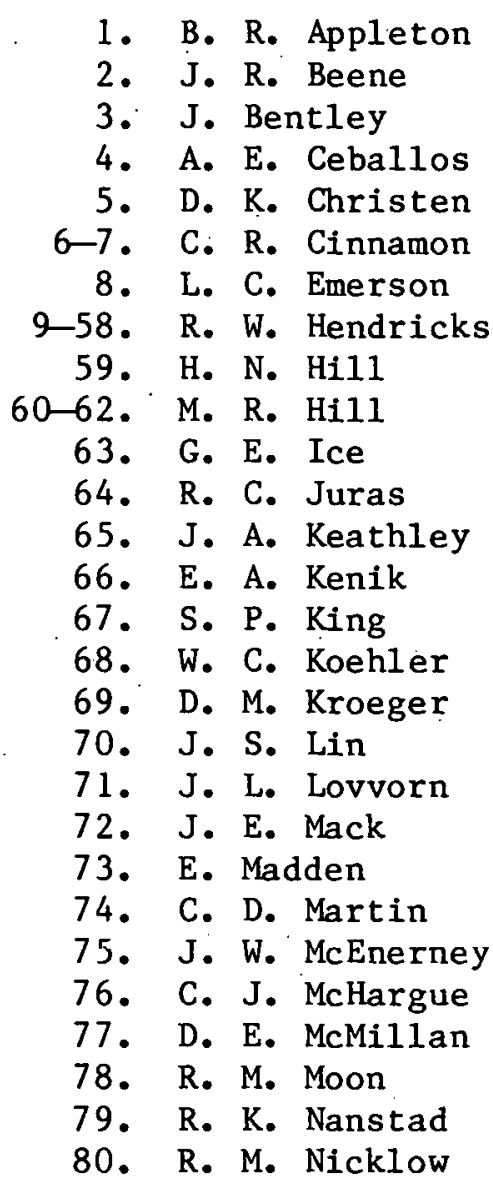

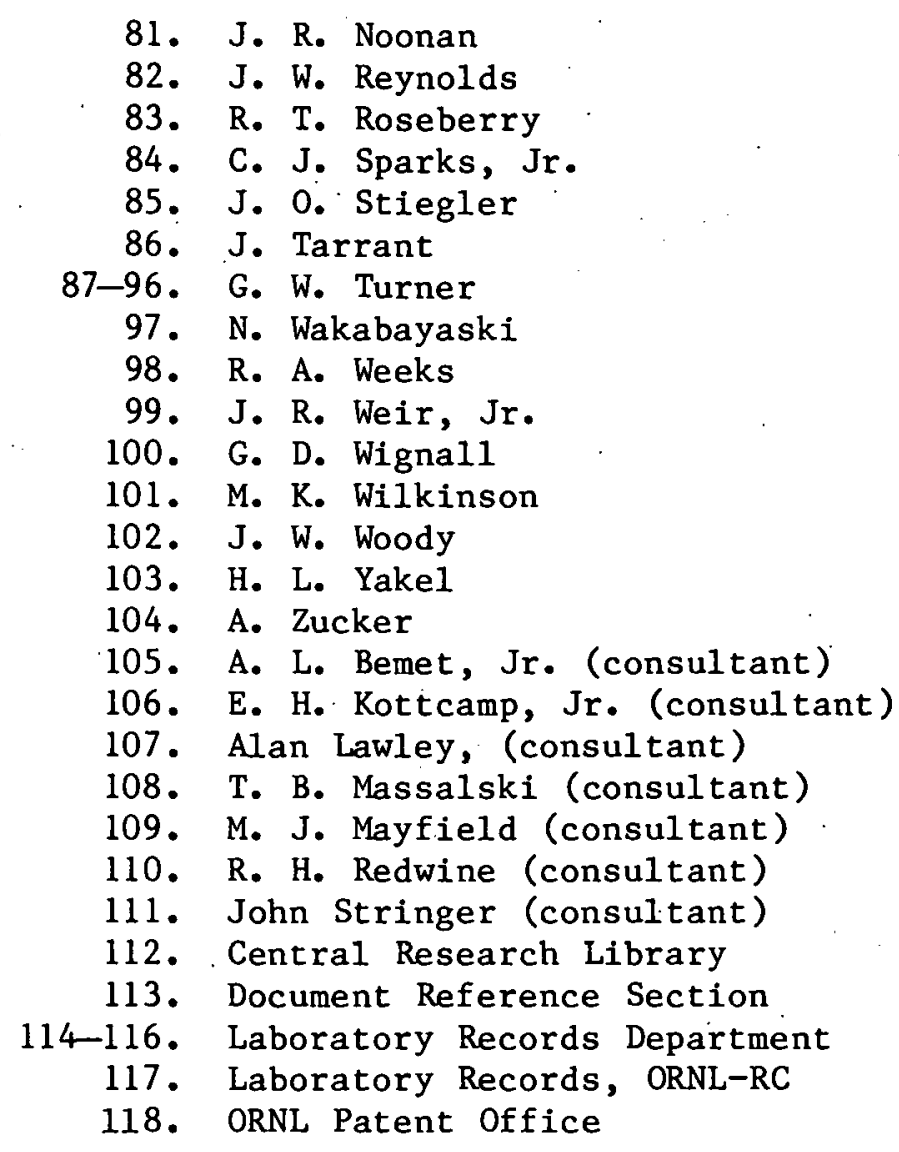

\section{EXTERNAL DISTRIBUTION}

119. B. W. Batterman, Division of Applied Physics, Cornell University, Ithaca, NY 14853

120. H. Brumberger, Department of Chemistry, Syracuse University, Syracuse, NY 13200

121. L. M. Costrel1, National Bureau of Standards, Washington, DC 20234

122. P. J. Flory, Department of Chemistry and Chem. Engr., Stanford University, Stanford, CA 94305

123. R. Heckmann, Kernforschungsanlage, GmbH, Institut fủr Fèstk'örperforschung, 517 Jül1ch, Postfach 1913, Jullich, West Germany

124. B. P. Schoenborn, Biology Division, Brookhaven National Laboratory, Upton, LI, NY 11973

125. C. G. Shull, Department of Physics, Massachusetts Institute of Technology, Cambridge, MA 02139 
126. J. L. Staudenmann, Iowa State University, Ames Laboratory, P. 0. Box 1129, Ames, IA 50010

127. R. S. Stein, University of Massachusetts, Polymer Research Institute, Room 167, Goessman Laboratory, Amherst, MA 01002

128. C. A. Wert, Department of Metallurgy, University of Illinois, Urbana, IL 61801

129-131. Department of Polymer Chemistry, Kyoto University, Kyoto 606, Japan

T. Hashimoto

H. Kawai

5. Suèhizro

132-133. Los Alamos Scientific Laboratory, P-8, Los Alamos, NM 87544 J. W. Scheer P. A. Seeger

134-137. National Science Foundation, 1800 G Street, N.W. Washington, DC 20550

N. M. Bikales

D. L. Mitche11

L. H. Nosanow

W. T. Oosterhuis

138. USDOE, Assistant Manager; ORO, Oak Ridge, TN 37830

139-140. USDOE, Department of Materials Sciences, Washington, DC 20545

L. C. Ianniello

D. K. Stevens

141-167. Technical Information Center, USDOE, Oak Ridge, TN 37830 